\title{
La actitud barroca en el discurso filosófico moderno
}

\author{
Bolivar Echeverria
}

\author{
Denn es gibt zwei Labyrinthe fur den \\ menscblichen Geist: das eine betrifft \\ die Zusammensetzung des Kontinuums, das \\ andre das Wesen der Freibeit. Das eine \\ wie das andre aber entspringt aus \\ derselben Quelle, nämlich aus dem \\ Begriff des Unendlichen.
}

Leibniz

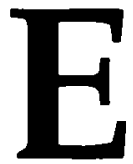

n sus lecciones sobre Leibniz, Heidegger reconoce una especial densidad en el pensamiento filosófico moderno y la atribuye a la necesidad que tiene de problematizar su tradición cristiana, de asumirla y al mismo tiempo tomar distancia frente a ella. ${ }^{1}$

En efecto, la nueva filosofía implicaba un intento de reformular radicalmente no sólo la temática sino los modos mismos del discurso filosófico; intento que, de una manera o de otra, tenía que pasar por una revisión de la tradición filosófica, en especial de aquella original, la de la Grecia antigua. Se trataba, sin embargo, de un recurso a los orígenes que no podía hacerse de manera directa; que debía atravesar por una crítica de la instancia administradora de esa tradición: la filosofia teológica y su formulación más acabada, la Escolástica medieval.

Vista como un fenómeno de la historia de la cultura y valorada de acuerdo con la función que cumplió en ella, la filosofía teológica de la Edad Media aparece como uno de los principales factores del surgimiento de un nuevo conjunto "clásico" de cánones discursivos, el de la cultura propiamente europea: ejecutora de la necesidad de universalizar el texto mítico judeo-cristiano, el de los dos testamentos de la Biblia - texto que por definición estaba atado a las singularidades de una lengua y una

${ }^{1}$ Martin Heidegger, Der Satz vom Grund, Pfullingen, 1957, p. 123. 
cultura naturales-, fue sin duda una construcción autoritaria. Fomentaba, desde su altura esotérica, el ejercicio libre de la razón individual, pero al mismo tiempo guiaba a ésta para que encontrara por sí misma los límites irrebasables de su acción; fue así una especie de techo protector bajo el que se gestó lentamente todo un modo peculiar de usar la razón, toda una nueva discursividad; aquélla que, modernizada de una cierta manera, habría de ser más tarde uno de los secretos de la europeización indetenible del mundo.

Mirada en sí misma, en cambio, la filosofía teológica se presenta como una creación sumamente frágil e inconsistente. Si algo la caracteriza en su constitución es el intento de llevar a cabo una combinación de dos intenciones teóricas incombinables - la filosófica, de un lado, y la teológica, de otro- y de hacerlo, además, con el fin de que una de ellas subordine a la otra: philosophia, ancilla theologiae. Se trata de un hecho discursivo híbrido que puede ser calificado de contradictorio en sí mismo debido a que pretende la interpenetración de dos tipos de producción de verdad completamente heterogéneos: el de la sabiduría oriental, que se alcanza a través de una hermenéutica de la revelación (mito); y el de la sabiduría occidental, que se obtiene a través de una crítica de la misma. Pretensión que, sin el impulso histórico cultural que la sostuvo, sería en realidad doblemente absurda: la interpretación de la palabra divina no necesita por sí misma de un logos que verse sobre la esencia de Dios (una teo-logía); y nada es más ajeno al logos filosófico, que se pretende de-velador, que una doctrina en la que la verdad ya está revelada.

Entre los cánones que la yuxtaposición de la teología y la filosofía aportó a la nueva tradición "clásica" del saber europeo se encuentra uno en especial, de resonancia platónica, que nos interesa subrayar aquí; según él, el hecho de que un discurso sea adecuado en el plano gnoseológico - que sea atinado, revelador, verdadero- incluye necesariamente (o debe incluir) el que sea también, de manera inmediata, un discurso adecuado en el plano ético - que sea constructivo, conveniente, bueno-. Se trata de un canon cuyo destino en la historia de la filosofia moderna resulta especialmente ilustrativo de uno de los rasgos más característicos de la totalización civilizatoria que llamamos modernidad: el humanismo, entendido como la tendencia del ser humano a inventarse una idea de sí mismo como "medida de todas las cosas", y no sólo en el plano cuantitativo como constante proporcional de las magnitudes naturales, sino como criterio cualitativo capaz de definir la realidad misma de lo real.

El nuevo "reclamo para el pensar" que dio lugar a la aparición del discurso filosófico moderno difería radicalmente de aquel que había dado lugar a la filosofia teológica. Aquello que es motivo de la extrañeza y el 
asombro filosóficos, que despierta a la voluntad de conocer y simultáneamente la crítica de esa misma voluntad, había dejado de estar recluido en el texto de la revelación, en el dogma, y se presentaba cada vez con mayor intensidad y frecuencia fuera de él, en fenómenos que él no había captado y para los que no disponía de nombres. Ya no era la vida eclesial, cerrada en si misma y de espaldas a la vida terrenal y su historia, el lugar desde donde se accedía a ese extrañamiento, sino la vida citadina, preocupada con las cosas terrenales -con sus problemas técnicos, sociales y políticos- y abierta la historia de un mundo de la vida que se encontraba en pleno proceso de recomposición general. ${ }^{2} \mathrm{La}$ nueva figura del mundo brillaba sobre el trasfondo de un gran desvaimiento de la figura vieja. Su rasgo característico, la presencia activa e individualizada de una sujetidad voraz, dotada de una voluntad apropiativa libre, es decir, abstracta, indiscriminada $e$ insaciable, se destacaba sobre el anquilosamiento y la debilidad de una voluntad colectiva de salvación eterna, que hacían del libre albedrío individual un simple trámite de aceptación de la miseria y el sufrimiento.

Podría llamarse epistemologismo al modo en que el humanismo de la civilización moderna se hace presente en el terreno del discurso filosófico. Presupuesto en la vida moderna y en la construcción que ésta hace de su mundo como "sujeto primero y auténtico", como "fundamento sobre el que todo se constituye", 3 el Hombre se afirma frente a lo otro convertido en Naturaleza, en algo que está ahí sólo en la medida en que responde al reto de su actividad apropiativa. ${ }^{4}$ Reto técnico que alcanza su mayor pureza en la ciencia experimental, en el discurso que propone representaciones cuantificables de lo desconocido, es decir, imágenes cuya capacidad de hacerse de las cosas al representarlas - y de provocar por tanto seguridad y certeza en el autor de su formulación-puede ser puesta a prueba y medida como lo es la productividad de un instrumento de trabajo. Más aún que en la transformación de la cultura política, el ímpetu y la libertad de despliegue del humanismo moderno se da en el desarrollo de la técnica exigida por el productivismo abstracto y en el cultivo de su quintaesencia: la ciencia como investigación, esto es, como descubrimiento, conquista y ocupación de lo otro por la imaginación cuantificante.

${ }^{2}$ Cf. Bernard Groethuysen, Die Entstebung der büryerlicben Weltund Lebensanschauung in Frankreich (1927), Suhrkamp, Frankfurt a. M. 1972, t. 1, p. 228.

${ }^{3}$ Martin Heidegger, Die Zeit des Weltbildes, en Holzwege, Frankfurt a. M. 1957, pp. 80-81; Die Frage nach der Tecbnik, en Vorträge und Aufsätze, Pfullingen 1954, pp. 24-28.

${ }^{4}$ La naturaleza se presenta como un cúmulo de cosas dotadas de un valor de uso que lo es únicamente para la producción; de cosas que sólo existen como soporte del trabajo humano en general, de aquella substancia que, al valorarlas para el mercado, las establece como dotadas también de un determinado valor de uso para el disfrute. 
El secreto de toda la recomposición moderna del mundo parecía por ello concentrarse en el ejercicio de la facultad cognoscitiva del ser humano y en los resultados del mismo; era el supuesto del que partieron los fundadores, F. Bacon y R. Descartes. De las más formalizadoras a las más empáticas, las distintas modalidades del conocimiento llegaron a componer el nuevo terreno en el que lo extraño y sorprendente que aficiona a la filosofía se daba de manera privilegiada. ¿Cuánto hay de objetividad y cuánto de ilusión en lo que conocemos? ¿Qué en ello es innato y qué propiamente adquirido? La preocupación por la consistencia, las variedades y los alcances del "mejor" de los conocimientos, el conocimiento científico, se presentó como la preocupación más genuina de los filósofos, y una tendencia epistemologista resultó entonces ineludible en su quehacer. Una tendencia que se volvió incluso excluyente, que intentó opacar, subordinar o eliminar a las otras tendencias de la inquietud filosófica, y que ha llegado a caracterizar al modo predominante de ejercicio del discurso filosófico en la época moderna.

¿Es posible, en general, sin traicionar la integridad del objeto de la inquietud filosófica, tratar de manera independiente el conjunto particular de cuestiones que atañen al entendimiento humano? En una rebeldía plenamente justificada contra la envejecida sujeción del problema de la verdad discursiva a las soluciones que los problemas del mantenimiento del orden religioso del mundo recibían desde el texto de la revelación divina, la filosofía epistemologista se inauguraba con una rotunda respuesta afirmativa a esta pregunta. El problema de la verdad (atingencia) del discurso puede y debe tratarse con independencia respecto del problema de la bondad (conveniencia) de su ejercicio -así como también respecto del problema de la belleza (vivencia) del mismo. Afirmación que implicaba, por supuesto, otra anterior, generalmente tácita: la actitud moral ante el mundo (así como el disfrute estético del mismo) no mantiene ninguna relación ontológica de interioridad o de constitución recíproca con la apropiación cognoscitiva que hacemos de él.

No todo, ni siempre lo mejor, ha sido sin embargo epistemologismo en el discurso filosófico moderno. Marginales - vencidos, desechadosotros modos de este discurso se encuentran también presentes en su his-

5 Cabe advertir que las obras de los filósofos concretos o los episodios concretos de discusión y creación filosófica no se inscriben de manera total o no coinciden plenamente con uno u otro de estos modos del filosofar; por el contrario, su riqueza singular reside justamente en el hecho de que el predominio de uno de estos -el epistemologismo, en este caso- se da en ellos como una tendencia que es el resultado de un conflicto permanente con los otros modos alternativos. 
toria. ${ }^{5} \mathrm{El}$ epistemologista ha sido el modo central porque ha sido zeitgemäss, ha caminado con la época o con lo que ha predominado en ella, el humanismo. Pero junto a él, unzeitgemäss o a contracorriente de la marcha del "progreso", otras propuestas de discurso filosófico han hablado a partir de otros proyectos de construcción moderna para el mundo de la vida; proyectos que sólo llegaron a realizarse a medias o que se realizaron y fueron después rebasados por el proyecto de la modernidad capitalista actualmente establecido. A una de ellas es tal vez posible denominar "barroca".

\section{II}

Resulta imposible hacer mención de un hecho humano, sea éste del remoto pasado o incluso del presente, sin legendarizarlo, sin adjudicarle una función dentro del relato de otros hechos que, junto con él, estarían componiendo un drama digno de narrarse, un "cuento real", más o menos explícito y coherente. Por esta razón, construir el concepto histórico de ese hecho, convertirlo en un acontecimiento explicativo y explicable, es siempre únicamente algo así como recoger el cristal que una determinada clave racional de cristalización ha logrado formar a partir de la materia proteica e inasible de su versión legendaria. Así sucede con ese hecho del siglo XVII europeo que consiste en el protagonismo de una cualidad dentro del mundo de la vida, la cualidad de "lo barroco".

Un cierto modo de comportarse, de ejercer la capacidad de "dar forma" a los actos y a las cosas, de arreglar el espacio y de ordenar el tiempo parece perfeccionarse, fortalecerse y prevalecer en ciertas sociedades de esta época, adoptando diferentes configuraciones particulares de acuerdo con las tradiciones culturales de las distintas regiones, a las distintas clases sociales y a los distintos campos de la actividad humana. Se trata de un modo de estar en el mundo cuyo plano "retórico" —el único que fue considerado por el discurso reflexivo de entonces- fue juzgado exclusivamente como una desviación del modo de dar forma que correspondería a la esencia del hombre; como una expresión del "mal gusto", de un intento fracasado de comportarse "como es debido"6. Lo barroco era la nueva versión, la versión moderna, de este mal gusto; su fracaso consistía en un exagerar $-\mathrm{y}$ no, como antes, en un quedarse corto- en el uso de la forma para domar al contenido. El modo de ser barroco no era el del hombre natural, del campo, insensible al artificio, sino el del hombre civilizado, citadino, insensible a la sencillez.

${ }^{6}$ Cf. José Antonio Maravall, La cultura del barroco, Barcelona, Ariel, 1980, pp. 187-190. 
El adjetivo barroco sólo dejó de ser un mero vehículo de esa intención peyorativa y pasó a sustantivarse en calidad de descripción - si se quiere imprecisa e incompleta, pero de todas maneras deslindante- del espíritu largamente incomprendido de una época histórica, cuando la teoría del arte lo sacó del campo de la crítica artística, en donde su uso no había sido abandonado, y comenzó a emplearlo para caracterizar todo un estilo, una época estilística o un período de la historia del arte. ${ }^{7}$ Sólo entonces apareció el problema de la definición de lo barroco. La tendencia espontánea del discurso reflexivo a la legendarización se vio enfrentada a una confusa lista de obras, documentos y supervivencias de toda clase -artísticos, literarios, del uso social e incluso de la actividad productivaque ostentaban la fama de barrocos y que ya no se dejaban identificar como simples objetos del "mal gusto moderno"; una lista por debajo de la cual ella debía sospechar la presencia escondida de un hecho dramático que le daba sentido y se expresaba en ella.

¿En qué consiste lo barroco? Muchas han sido durante este siglo las claves de inteligibilidad que la teoría y la historia de la cultura y el arte han propuesto para construir una imagen conceptual coherente a partir del magma de hechos, cualidades, rasgos y modos considerados propios, característicos o peculiares de lo barroco. Como es usual, al proponer su principio de sintetización de este panorama inasible, todas ellas ponen primero en juego distintas perspectivas de abordaje del mismo, las combinan de diferente manera y enfatizan alguna de ellas. ${ }^{8}$ Tienen en cuenta, por ejemplo: a) el modo en que se inscribe a sí mismo, en tanto que es una donación de forma, dentro del juego espontáneo o natural de las formas y dentro del sistema de formas que prevalece tradicionalmente; b) la elección que hace de una figura particular para el conjunto de posibilidades de donación de forma, es decir, la amplitud, la consistencia y la jerarquización que él propone para su propio "sistema de las artes"; c) el tipo de relación que establece con la densidad mítica del lenguaje y con la densidad ritual de la acción; d) el tipo de relación que establece entre los contenidos lingüisticos y las formas lingüisticas y no lingüisticas.

7 Criticada y tal vez superada en muchos aspectos, la obra de Heinrich Wölfflin -sobre todo Rennaissance und Barock (1908) y Kunstgeschichtlicbe Grundbegriffe (1915)- no deja de ofrecer la descripción más sistemática y de ser por tanto la teoría de referencia indispensable de todo tratamiento de lo barroco en el arte.

${ }^{8}$ Corrado Ricci (1906), h. Wölfflin (1908 y 1915), Benedetto Croce (1929), Werner Weissbach (1921), Eugenio D'Ors (1934?), Henri Focillon (1936), Emile Mâle (1951), Víctor Tapié (1957), Helmut Hatzfeld (1927-72), José Antonio Maravall (1975), Santiago Sebastián (1981) son los autores más representativos de las distintas aproximaciones al fenómeno de lo barroco. 
Para sostener la idea que proponemos en estas páginas resulta suficiente tener en cuenta lo barroco tal como se presenta en la primera de estas perspectivas de abordaje. Es decir, como una voluntad de forma atrapada entre dos tendencias contrapuestas - la del desencanto respecto del conjunto de las posibilidades clásicas, es decir, "naturales" o espontáneas, de dar forma a la vida y la de la afirmación del mismo como insuperable-y empeñada en el esfuerzo trágico, incluso absurdo, de conciliarlas mediante un replanteamiento de ese conjunto como diferente y sin embargo idéntico a sí mismo. Lo barroco parte de la necesidad de la transgresión como síntesis del rechazo y la fidelidad al modo tradicional de tratar a las cosas como material conformable, pero mientras su hermano gemelo, el manierismo, hace de la fidelidad un pretexto del rechazo, él en cambio hace de éste un instrumento de la fidelidad. ${ }^{9}$

El comportamiento barroco se desdobla, en verdad, en dos pasos diferentes, de sentido contrario, pero simultáneos. Los innumerables métodos y procedimientos que se inventa para llevar a las formas creadas por él a un estado de intensa fibrilación - los mismos que producen aquella apariencia "bizarre" (ornamentalista, exagerada y absorbente) que lo distingue- están encaminados a despertar en los cánones clásicos, que él tiene por absolutos, una dramaticidad originaria que sospecha dormida en ellos. Desesperado ante el agotamiento de la única fuente posible de sentido objetivo, la somete a una serie de pruebas o tentaciones destinadas a restaurar en ella una vitalidad sin la cual la suya propia carecería de sustento. Sin embargo, al mismo tiempo, la introducción de una modificación significativa, de un sesgo propio, que él hace ineludiblemente al despertar la dramaticidad clásica, tiene ella misma una dramaticidad propia, que no es derivada y que incluso es tal vez la única que existe realmente. ${ }^{10}$ Por esta razón, el comportamiento barroco parte de la desesperación y termina en el vértigo; en la experiencia de que la plenitud que él buscaba para sacar de ella su riqueza no se llena de otra cosa que de los frutos de su propio vacío.

Combinación conflictiva de conservadurismo e inconformidad, de respeto al ser y connato nadificante, el comportamiento barroco encierra una reafirmación del fundamento de toda la consistencia del mundo, pero una reafirmación que, paradójicamente, al cumplirse, se descubre fundante de ese fundamento, es decir, fundada y sin embargo confirmada en su propia inconsistencia. Descrito de esta manera, el comportamiento

9 Cf. Arnold Hauser, El manierismo, Madrid, Guadarrama, 1965, p. 297.

${ }^{10}$ Cf. Walter Benjamin, Ursprung des deutschen Trauerspiels (1925), Suhrkamp, Frankfurt a. M. 1972 , p. 100 . 
barroco que se muestra en la actitud de una voluntad de forma artística respecto del universo de formas estéticas establecido, resulta homólogo del ethos que caracteriza a uno de los distintos tipos de modernidad que se han presentado históricamente. ${ }^{11}$

La asociación entre ética protestante y capitalismo, sumada a la convicción de que es imposible una modernidad que no sea capitalista, han llevado a la idea de que la única forma imaginable de poner un orden en el revolucionamiento moderno de las fuerzas productivas de la sociedad humana es la que viene dictada por la "ética protestante". ${ }^{12}$ Sin embargo, un examen más atento de la historia del capitalismo, de aquello respecto de lo cual la ética protestante revela ser más realista, más adecuada o acorde, muestra que éste ha sido susceptible de otras aceptaciones y otros acuerdos, sin duda menos realistas que los de ella, pero no menos reales.

La forma objetiva del mundo moderno, la que debe ser asumida ineludiblemente en términos prácticos por todos aquellos que aceptan vivir en referencia a ella, se encuentra dominada por la presencia de la realidad o el hecho capitalista; es decir, en última instancia, por la pre-sencia de un conflicto permanente entre las tendencias contrapuestas de dos dinámicas simultáneas, constitutivas de la vida social: la de ésta en tanto que es un proceso de trabajo y de disfrute en torno a valores de uso, por un lado, y la de la reproducción de su riqueza, en tanto que es un proceso de "valorización del valor abstracto" o acumulación de capital, por otro; conflicto en el que, de manera permanente, la primera se sacrifica a la segunda y se somete a ella. Se trata de un hecho inevitable, que debe ser integrado en la construcción del mundo de la vida, en el ethos o comportamiento espontáneo que pone la "armonía" usual y segura de la existencia cotidiana, y que es integrado, efectivamente, pero no de una sola manera, sino de varias.

A la manera más realista de asumir como "natural" el hecho capitalista (la que inspira a la ética protestante), que considera que la vida del valor de uso está plenamente representada por la vida del valor capitalista, que reconoce una eficacia y una bondad insuperables en la conjunción de ambas y afirma la imposibilidad de un mundo alternativo, se oponen otras - como pueden ser la manera clásica o la romántica- entre las que conviene destacar aquí, justamente, la manera barroca. El arte barroco puede prestarle su nombre porque, como él -que acepta la incuestionabilidad del canon formal, pero lo emplea de tal manera que, al despertar el gesto

11 Cf. B. Echeverria, Modermidad y capitalismo, México, Era, 1993.

12 Es la idea que subyace en la famosa obra de Max Weber, Die protestantische Etbik und der Geist des Kapitalismus, y que prevalece en la mayoria de las obras que tratan la "cultura del capitalismo". 
petrificado en él, revitaliza el conflicto salvado por esa incuestionabilidad-, ella también es una "aceptación de la vida hasta en la muerte". ${ }^{13}$ Es una estrategia de afirmación de la corporeidad del valor de uso que parte del reconocimiento de la misma como sacrificada para - invirtiendo como bueno al "lado malo" por el que avanza la historia - hacer de los restos del sacrificio el material de una nueva corporeidad.

\section{III}

La actitud barroca se hace presente en el discurso filosófico moderno a partir de la tradición de aquella teología especial que fue alentada por la Compañía de Jesús durante los dos siglos (1650-1850) en que se empeñó en restaurar - en contra de los efectos de la Reforma religiosa en el norte de Europa- la vigencia central de la Iglesia católica como medio de socialización y como entidad política.

La Compañía de Jesús partía de un reconocimiento de lo evidente. La capacidad de la actividad moral-religiosa de instaurar la socialidad de las comunidades reales había disminuído sustancialmente: la fuerza de sintetización o de religamiento de los individuos sociales había abandonado el templo y salido al mercado, el mismo que se orientaba ya por la valorización capitalista del valor económico. El ejercicio del libre albedrío de los individuos sociales en la conducción de su vida -organizado tradicionalmente por la Iglesia apostólica sobre la base de una articulación metonímica con Dios- había dejado de ser un espacio de indecisión, y por tanto de constitución, en el que estuviera en juego el otorgamiento de la gracia divina y junto con él el orden político de la vida social. ${ }^{14}$ Nuevos agentes de un nuevo mundo descubrían en sí mismos una voluntad apropiativa ilimitada y la volcaban sobre el mundo terrenal en pleno desentendimiento de esa dimensión del libre albedrío. Creían comprobar en la buena fortuna del hombre de empresa que la administración de la gracia divina estaba ya decidida (predestinada) de una vez por todas y transformaban al libre albedrío - aligerándolo del peso ontológico que lo agobiaba y le restringía sus posibilidades de elección- en mero atributo de esa voluntad de apropiación, encauzada en la búsqueda pragmática de sus destinos puramente individuales.

La utopía de una modernidad católica, defendida desde el Concilio de Trento por los seguidores de Ignacio de Loyola, pretendió, hasta su fracaso

13 Este rasgo, que coincide con la definición que Georges Bataille da del erotismo (L'érotisme, Minuit, París 1957, p. 19), conecta a la actitud barroca con una afirmación constitutiva de lo humano en medio de "lo otro".

"4 Bernhard Groethuysen, op. cit., t. ı, p. 154. 
definitivo en el Siglo de las Luces (o de la Revolución Industrial), oponer a la marcha caótica e injusta de la vida social moderna -dinamizada por el progreso en la producción y la circulación de los bienes- la acción de un sujeto capaz de interiorizarse en esa marcha, de dotarla de sentido y de guiarla hacia el bien: la Iglesia. Sujeto que, por su parte, sólo podía ser tal efectivamente si se reafirmaba en su propia necesidad y reconquistaba su propio carácter, el de mediador de la gracia divina. La propaganda fide de la Compañía de Jesús no se encaminaba solamente en el sentido de la expansión de la Iglesia en el mundo social, sino, sobre todo, en el sentido de una refundación y una reactualización de sí misma, es decir, de su identificación con Dios como presencia efectiva de lo sobrenatural en su pacto con la comunidad humana.

La idea planteada por Luis de Molina y desarrollada por Francisco Suárez - calificada de herética por ortodoxos y protestantes- de que hay una scientia media en Dios, la que conoce el mundo en estado de infinidad de probabilidades pero que no es suficiente para determinar su efectuación, se encaminaba a defender la razón de ser de la Iglesia insistiendo en aquello que le da su función: la presencia del libre albedrío en el ser humano y su intervención activa en el otorgamiento de la gracia divina. ${ }^{15}$ En efecto, la gracia divina sólo podrá requerir de una entidad histórico concreta de mediación en el caso de que ella misma esté aún en juego y no sea ya una predestinación o un destino; sólo que se encuentre aún en proceso de darse o constituírse y deje por lo tanto al individuo humano la capacidad de asumirla libremente. Si la Creación estuviera ya terminada, y por tanto el sentido y el valor de toda acción individual se encontrara determinado de una vez por todas; si hubiera predestinación, sólo habría Dios en tanto que Obra de Dios y no en tanto que Dios en acto, y la Iglesia resultaría superflua.

Tal vez en ninguna obra del discurso filosófico moderno la actitud barroca se pone de manifiesto con mayor intensidad que en la obra de Leibniz. ${ }^{16}$ Es una actitud que toma forma a partir de la vía abierta por la teología de la Compañía de Jesús hacia lo que podría llamarse una revitalización del maniqueísmo originario que constituye la estructura dramática profunda del mito judeo-cristiano.

15 Cf. Georges Friedmann, Leibniz et Spinoza, Gallimard, París 1962, p. 260.

16 Gilles Deleuze defiende esta idea en su penetrante ensayo Le pli (Leibniz et le baroque) (Minuit, París 1988). Estas páginas indican una manera de completar la aproximación que interpreta la predilección del barroco berniniano por la forma del pliegue y la conecta con la teoría de las mónadas y la armonía universal mediante otra que ve la actitud implicita en la voluntad de forma del barroco como una actifud compartida por el filosofar de Leibniz. 
La teología de los jesuitas rompe con la paz de esa secuencia establecida por la doctrina medieval, de acuerdo a la cual Dios (la substancia luminosa, buena) ha vencido sobre el Diablo (la substancia oscura, mala), que se habría introducido en su Creación a través del pe-cado humano, y lo mantiene alejado de ella gracias al sacrificio de Cristo. Despierta la virulencia del conflicto que ella esconde: el Diablo estaría aún en proceso de ser vencido, no habría dejado de estar activo, seguiría siendo sujeto podría invertir el sentido de la Creación-; por ello, el ser humano puede todavía decidir entre él y Dios, y sólo al hacerlo por este último valida en verdad el sacrificio de Cristo. La redención sería una empresa que está por triunfar, pero que todavía no lo ha hecho; una empresa en la que el individuo humano puede intervenir.

Leibniz pertenece a la tradición marginal del discurșo filosófico moderno, aquélla que no cree suficiente un abandono de la filosofía teológica que no sea capaz de superar la interpenetración de lo moral y lo gnoseológico que hay en ella, y se contente con desconocer tal interpenetración y cultivar por separado alguno de los dos elementos (o los dos). ${ }^{17}$ Lo característico de su pensamiento está justamente en aquello que, desde el modo epistemologista del filosofar, se ha visto como una debilidad accesoria del mismo, en algo que sería una incapacidad de dar el último paso en la ruptura definitiva con la problemática pre-moderna del discurso filosófico, de echar por la borda el lastre teológico y atenerse a la imagen de lo real propuesta por el saber científico moderno.

Leibniz intenta conciliar la explicación "por la causalidad de la esencia y la explicación 'por la razón moral'". Según él, la pretensión de existir, la tendencia a actualizarse, es propia de todas y cada una de las innumerables mónadas o substancias simples a las que el entendimiento puede reducir la consistencia del mundo. Sin embargo, no todas las substancias son composibles con cualquier otra - no todos los posibles lógicos son compatibles entre sí-: algunas "s'entrempêchent". Hecho que las reduce a la impotencia, las vuelve incapaces de actualizarse por sí mismas y las condenaría, en principio, a permanecer para siempre como simples posibles. Es necesario un "mecanismo metafísico" que, entre todas las series o armonías que pueden dar un orden a las substancias simples, esté seleccionando una que es la única real. Un mecanismo que tiene que obedecer a un "racionalismo moral" y que no puede ser otro que la bondad divina, la decisión divina de crear. ${ }^{18}$ "La incomposibilidad de las esencias

17 Cf. Georges Friedmann, op. cit., p. 219.

${ }^{18}$ Gottfried W. Leibniz, La Monadologie, Nr. 53, en: Essais de Teodicée, Aubier, Paris 1962, p. 499. 
vuelve necesaria una elección inteligente. La causalidad lógica toma la forma de un determinismo moral". ${ }^{19}$

Leibniz insiste en el canon de la filosofía teológica que confunde lo verdadero (o revelador) con lo bueno (o conveniente). Pero la ontologización de lo ético o etización de lo ontológico que está implícita en el planteamiento anterior no se reduce simplemente a reformular ese canon para ponerlo al día. Es el resultado de un monumental trabajo de swinging barroco en el universo de los conceptos tradicionales; un volver obsesivo sobre todos los temas de la filosofía teológica con la intención de despertar en ellos su núcleo problemático: la voluntad de combinar la definición (grecorromana) del ser de los entes como presencia espontánea con la (judeo-cristiana) que lo concibe como presencia provocada; de juntar la teoría filosófica con la sabiduría hermenéutica; de llegar incluso a unificar un tipo de discurso que confía más en el habla —en el uso del código y en la mitopóiesis - con otro que confía más en la lengua -en el código y en su coraza de mitos.

No sólo descifrar, sino descubrir la totalidad de lo real como Creación: ésta es la pretensión "clásica" del discurso filosófico desarrollado en la Edad Media del Occidente europeo. Es la pretensión que Leibniz replantea al revolucionar la filosofía teológica para convertirla en una "teodicea", en un alegato por la "causa de Dios", destinado a defenderlo a través del examen de su obra. Se trata de una revolución paradójica, en la que la actitud barroca se delinea con claridad: una destrucción hecha para reconstruir lo que destruye, y no para sustituirlo. Un proceso que alcanza su punto culminante en la puesta en crisis de esa pretensión "clásica" y que implica, por lo tanto, una revitalización del conflicto entre la duda y el descreimiento, entre el convencimiento y la fe. Que trae consigo también el vértigo de una experiencia en la que el acto de perder la fe y el de recobrarla parecen ser uno solo.

Explicar es dar la razón suficiente de la presencia de una cosa, sin caer en contradicción. Peru basta reconocer que cada cosa ts singular, única e irrepetible, para verse obligado a dar un paso más en esta definición del explicar. Explicar debe consistir, no en decir por qué algo existe en lugar de otra cosa que podría remplazarla, sino "por qué algo existe en vez de lo antes que] nada" (curaliquid potius existat quam nibil) ${ }^{20}$ Explicar una cosa a la que nada puede sustituir es dar la razón de ser de su singularidad cualitativa. Llevada a su extremo, practicada con radicalidad, esta definición

19 Jacques Jalabert, Introduction, en: G.W. Leibniz, op. cit., p. 17.

20 Pbilosopbische Abbandlungen, VIII, en: Die philosopbiscbe Schriften von G. W. Leibniz (H. v. C.J. Gerhardt), Berlin 1890, t.vit, p. 289. 
de la esencia del conocimiento humano, que parece obedecer a necesidades puramente operativas, llega a topar con un límite ontológico. El mundo real y su historia, lo mismo que cada persona real y su vida, es, en su totalidad cualitativa, único e irrepetible. ¿Cuál es la razón de ser de su singularidad? ¿Por qué es él y no más bien nada? ¿Cuál es, en general, la razón de que lo que es, tal como es, sea?

Que lo que hay sea un plus del "algo" de una substancia o que sea un minus de su "nada" debería ser, en principio, indiferente para su percepción. No obstante, así como el reconocimiento por el ojo humano de la representación fotográfica de un objeto sólo es tal cuando ella está en positivo ("revelada") y es en cambio desconocimiento cuando está en negativo, así también la percepción de lo cualitativo sólo es tal cuando lleva, ella misma, un sentido o tendencia positivos, una preferencia fundamental por el "algo"; cuando, para ella, la "nada" sólo es concebible como una disminución, una falta o un "desfallecimiento" del "algo". Como dice Heidegger ${ }^{21}$, en Leibniz encontramos, avant la lettre, una "crítica de la razón pura". Según ella, la actitud afirmativa, la aceptación que asume el hecho de que lo que es sea, es la principal o fundamental condición de posibilidad a priori del conocimiento humano. La existencia misma del discurso requiere del optimismo. El optimismo, es decir, la "complicidad" con aquella voluntad casual o infundada que está decidiéndose espontáneamente por el ser y contra la nada: la "complicidad" con Dios - "Razón universal y Bien supremo".

Leibniz nunca afirmó, como lo decía Voltaire, que "tout allait au mieux" en el "meilleur des mondes posibles". ${ }^{22}$ Su optimismo es relativo. El mal metafísico forma parte de la creación, porque la imperfección, la negatividad, la falta de existencia se encuentra en todos los posibles. ${ }^{23}$ De nuestro mundo puede decirse que "es el menos imperfecto de los mundos posibles" porque al menos existe. ${ }^{24}$ Pero, sobre todo, su optimismo reside en la afirmación de que la singularidad del mundo real está en proceso de configurarse y que esto acontece a través de una elección dentro de un campo abierto de posibilidades de sí misma. Podemos saber - se diría a partir de ella-, si suponemos la existencia de Dios (y su bondad), que este mundo es el mejor, pero también, si prescindimos de esa suposición, que al menos no es el único posible. Su "optimismo"

\footnotetext{
${ }^{21}$ Martin Heidegger, Der Satz vom Grund, p. 124.

${ }^{22}$ Voltaire, Dictionnaire philosophique, entrada: Bien (tout est), Flammarion, París 1929, p. 54.

${ }^{23}$ Cf. Gottfried W. Leibniz, Von dem Verbängnisse, en: Haupschriften zurGrundlegung der Pbilosophie, Hamburg, F. Meiner, 1966, p. 133: "Zwar wir hatten es lieber, wenn auch kein schein des Bösen überbliebe un die Sachen so gebessert wären..."

${ }^{24}$ Gottfried W. Leibniz, Theodicée..., Parte II, 226, p. 264.
} 
invita a percibir lo dado como pudiendo no estarlo, como reductible a un estadio anterior de su presencia; a vivir lo real sólo como posible: como un posible entre otros.

\section{棌粠}

"Combien l'optimisme de Leibniz est étrange"25, dice Deleuze. Extraña modernidad, diríamos, aquella utópica desde la que habla. El intento de Leibniz, pensamiento y ejemplo, muestra al discurso crítico un modo de salir de la asfixia a la que le condena la aceptación del carácter insustituible de la modernidad establecida. La suya fue una modernidad que se quedó en el camino pero que nos ilustra acerca de que la que está ahí no fue ni es la única posible.

25 Gilles Deleuze, op. cit., p. 92. 